Short communication

\title{
Storage of whole-tree chips from high-density energy plantations of Eucalyptus in Brazil
}

\author{
Humberto de Jesus Eufrade Junior*, Guilherme Oguri, Raoni Xavier de Melo, \\ Adriano Wagner Ballarin, Saulo Philipe Sebastião Guerra
}

Sao Paulo State University, College of Agricultural Sciences (UNESP/FCA), Jose Barbosa Barros St 1780, Botucatu, Sao Paulo, Brazil

\section{A R T I C L E I N F O}

\section{Article history:}

Received 11 March 2016

Received in revised form 16 June 2016

Accepted 8 July 2016

Available online 2 August 2016

\section{Keywords:}

Wood chips piles

Drying period

Daily moisture change

Storage systems

\begin{abstract}
A B S T R A C T
In this paper, the drying of whole-tree chip (WTC) storage from young Eucalyptus plantation managed at short-rotation coppice in Brazil was studies. The biomass was converted from high-density energy plantations of Eucalyptus grandis at 2 years old into four piles. Wood chip particles had 5, 15, and $30 \mathrm{~mm}$ length were disposed on a paved surface to evaluate the effect on the chip drying. An additional covered pile (30-mm wood chip) was installed to evaluate the effect of coverage condition. The non-ventilated and uncovered piles were not affected by WTC length, and the final moisture content (MC) was 48.4 $-53.5 \%$ and temperature inside the piles (storage temperature) was approximately $36{ }^{\circ} \mathrm{C}$. However, the coverage showed beneficial effect on drying wood chip process, collaborating to keep the MC lower than $35 \%$, conventionally recommended for energy purposes. Among storage systems studied, the higher daily moisture content was assigned to covered pile, about $0.197 \%$ day $^{-1}$ during the first 30 days. This paper can be used as a reference for further studies with wood chip pile storage at tropical conditions.
\end{abstract}

๑) 2016 Elsevier Ltd. All rights reserved.

\section{Introduction}

Due to its energetics aspects, the concern about forest biomass is increasing worldwide. In Brazil, high-density energy wood plantations managed on short-rotation coppice (SRC) are alternatives to achieve better target yields and produce a variety of energy assortments, including firewood, woodchips and hog fuel [1]. Harvesting of these dedicated energy crops included all above-ground biomass that was chipped and used for energy and not debarked stems, as in conventional plantations [2]. The woodchip may vary its length and shape according the type of chipper [3].

These forest systems use fast-growing species, high-density planting, and short rotations [4]. Owing to silvicultural aspects, the Eucalyptus species becomes attractive for this final use; moreover, the Brazilian weather offers ideal conditions for its crops [5]. As a result of this positive adaptability of Eucalyptus SRC, a higher planting density of 7000 trees ha $^{-1}$, reached yields of up to $100 \mathrm{t}$ dry matter (DM) ha ${ }^{-1}$ for 2-3 years cycles [1]. Currently, Eucalyptus

\footnotetext{
* Corresponding author.

E-mail addresses: hdjejunior@gmail.com (H.J. Eufrade Junior), guioguri@gmail. com (G. Oguri), raonimelo@hotmail.com (R.X. de Melo), awballarin@fca.unesp.br (A.W. Ballarin), ssguerra@fca.unesp.br (S.P.S. Guerra).
}

planted forest occupies an area of 5.56 million hectares in Brazil [6], which substantial majority area is managed conventionally (about 1667 trees $\mathrm{ha}^{-1}$ ) for pulp and paper production.

The fresh biomass harvested had high moisture content (MC), which affect negatively the wood supply chain logistics as harvest season, solid volume of biomass material to be harvested in each period, number of truck loads delivered to the power plant, the period of storage in the field, and others [7].

The storage appears as an opportunity to decrease the MC. However, the behavior of wood chip pile drying at tropical conditions is not quite known. Thus, there is a lack of information in the literature at same weather conditions.

In addition, woodchip pile temperature is a crucial factor during the storage time of fresh forest residues [8]; and higher temperature implies faster biological degradation rate of woodchip and, as a consequence, prone to a rapid decay [9]. According to Kofman [10], temperatures in the piles started at $10-20{ }^{\circ} \mathrm{C}$ and can reach more than $90{ }^{\circ} \mathrm{C}$, but rarely will take a self-combustion. Therefore, the storage affects both the biomass quality (physical and chemical properties) and logistic costs [11,12].

Major information about wood chip piles were obtained from European and North-American studies, and cannot be extended, at first moment, to tropical conditions. Published works, such as those reported by Brand et al. [13] and Zanuncio et al. [14] in Brazil, 
focused only on storage of logs wood.

Hence, the aim of this study was to evaluate the drying behavior under different storage systems of young Eucalyptus from SRC in Brazil. This evaluation was based on monitoring MC and temperature of whole-tree chip (WTC) piles, gauging the effect of length size and coverage.

\section{Materials and methods}

\subsection{Local description}

This work was carried out in Botucatu city $\left(22^{\circ} 50^{\prime} 21^{\prime \prime} \mathrm{S}\right.$ and $48^{\circ} 25^{\prime} 20^{\prime \prime} \mathrm{W}$ ) located at São Paulo state, Brazil. The plantation grew on low drained Nitossoil, flat land, and an average altitude of $790 \mathrm{~m}$ asl. Mean annual precipitation around $1400 \mathrm{~mm} \mathrm{year}^{-1}$, and an annual average temperature of $20^{\circ} \mathrm{C}$.

The biomass was harvested from short rotation forest described in Table 1.

\subsection{Harvest and chipping}

The chosen machine was a New Holland FR9060 forager machine coupled with NH 130FB coppice header. Cut-and-chip system has main features as stems base cutting and processing the whole tree into chips [15]. The base-cutter is performed by two circular saws at, approximately, $5-\mathrm{cm}$ above ground running out at $3000 \mathrm{rpm}$, which results clean cut on stump-promoting healthy regrowth. After cutting base, the stems are conducted to the drum chipper through infeed rollers. Drum chipper is located inside the forager, and is divided in two sections fitted with eight knives on each section. Chip length can be chosen from the operator's seat to any value between 5 and $30 \mathrm{~mm}$. The wood chip are engaged and discharged by the blower through the outlet pipe toward to the truck. More details about harvester set can be obtained in Guerra et al. [16].

\subsection{WTC piles and sampling}

The WTC piles $(150 \times 200 \times 300 \mathrm{~cm})$ were set up in a cemented floor (used for drying coffee beans) in trapezoidal shape. Three uncovered $9 \mathrm{~m}^{3}$ piles were installed in different conditions of chip length $(5,15$ and $30 \mathrm{~mm})$. In addition, covered pile of $30 \mathrm{~mm}$ of chip length was installed in the shed covered to evaluate the effect of coverage condition. WTC piles were shaped and sized according of trailer load capacity available at harvest moment. The height of the covered structure was determinative to choose a suitable trailer load in order to fit during the woodchip unloading.

To determine the Moisture content (MC), three composite samples were collected from pile at least three different points equally divided by height of size - top, middle and bottom $(30 \mathrm{~cm}$

Table 1

Forest characterization.

\begin{tabular}{lll}
\hline Field & Unit & \\
\hline Specie & & Eucalyptus grandis \\
Clone & & $\mathrm{G}-21$ \\
Age & year & 2 \\
Density planting & trees ha & 6667 \\
Tree height & $\mathrm{m}$ & 9.6 \\
DBH & $\mathrm{cm}$ & 6.4 \\
Basal area & $\mathrm{m}^{2} \mathrm{ha}^{-1}$ & 23.5 \\
Yield productivity & $\mathrm{t} \mathrm{DM} \mathrm{ha}^{-1}$ & 24.3 \\
Wood basic density & $\mathrm{kg} \mathrm{m}^{-3}$ & 355 \\
Whole-tree HHV & $\mathrm{MJ} \mathrm{dry} \mathrm{kg}^{-1}$ & 17.5 \\
\hline
\end{tabular}

Note: DM - dry matter, DBH - diameter at breast height, HHV - higher heating value. above ground); for each internal region of pile - surface $(0-50 \mathrm{~cm})$, intermediate $(50-100 \mathrm{~cm})$ and center $(100-150 \mathrm{~cm})$, totalizing at least nine different sampling positions. The MC of composite samples was obtained according ASTM E871-82 [17] in the laboratory.

The temperature inside the piles (or storage temperature) was measured by a three fixed thermocouples type $\mathrm{T}$ installed inside on middle pile size at same internal regions of pile cited above. Sampling scheme was shown in Fig. 1.

The piles were monitored during the observation period started on 6th June 2013 and ended on 11 October 2013, totalizing 126 days. The study comprised the whole winter season (the first 85 days of experiment) and the initial of spring season (the last 41 days of experiment).

Due to an atypical initial of rainy winter, the drying period was divided according the amount of precipitation detailed in Table 2 . The initial period was counted after installation of piles in the field and its thermocouples, about 2 days after harvest.

In addition, the daily moisture change (DMC) was calculated by Equation (1). It is defined as the amount and direction to which moisture changes every day during the storage period and should be connected with calendar periods [18]. This is relevant, if we consider the use of DMC in further studies for construction of a forecasting algorithm for natural drying of energy wood in forest storages.

$\mathrm{DMC}=\frac{M C}{N D}$

where,

$\mathrm{MC}=$ Moisture change during the period considered, \% units;

$\mathrm{ND}=$ Number of days in period.

\subsection{Statistical procedures}

The piles were grouped separately to evaluate the effect of chip length (uncovered piles of 5, 15, and $30 \mathrm{~mm}$ ) and coverage (only $30 \mathrm{~mm}$ wood chips pile) on moisture content and storage temperature during drying period.

Normality of data was assessed using Shapiro-Wilk's test $(p<0.05)$. Analysis of variance (ANOVA), complemented by Tukey's test (significant at $p<0.05$ ), evaluated the effect of chip length and coverage.

Basic statistic (central tendency) analyzed the DMC of storage systems.

\section{Results and discussion}

\subsection{Effect of chip length}

The chip length did not affect MC. On the other hand, the storage temperature was affected by greater length of chips at 30 days of storage as shown in Table 3.

It was observed greater variations of moisture content among internal regions of pile, up to $33.3 \%$. This can be explained due to more influence of environmental conditions on surface region than intermediate and center regions that had close results of MC and temperature over drying period.

The non-ventilated and uncovered piles did not reach 35\% MC, conventionally recommended for energy purposes. Differently than observed for Eucalyptus urophylla and Corymbia citriodora debarked logs after 90 days of drying logs in Brazil [14]. Thus, cut-to-chip process used in SRC systems suggest that biomass should be 

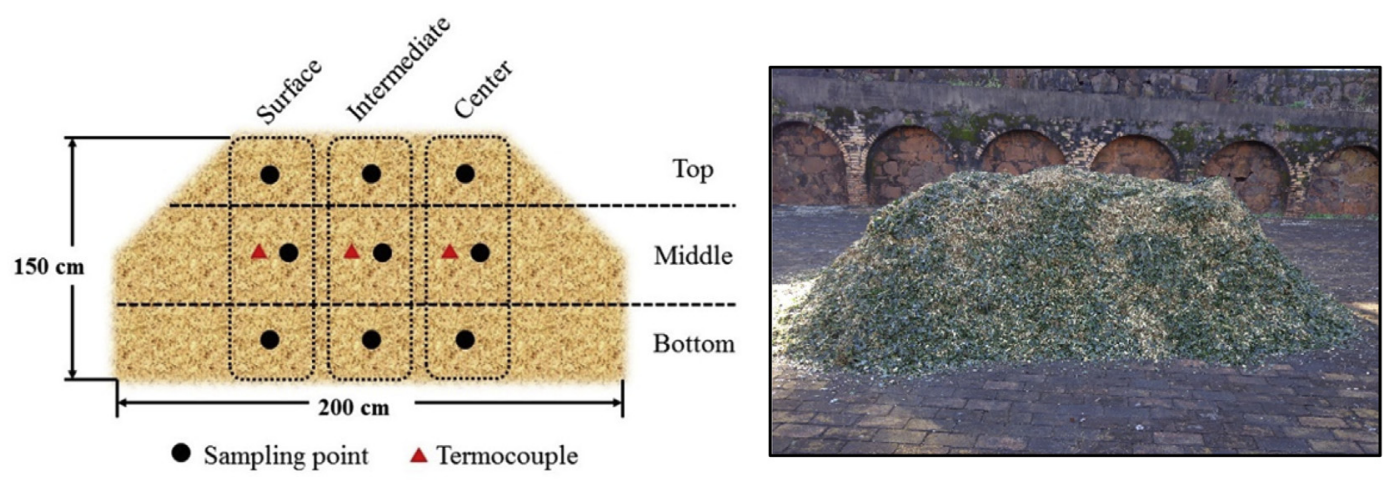

Fig. 1. Schematic drawing of the whole-tree chip pile and the position of sampling points (left) and the real whole-tree chip pile (right).

Table 2

Weather conditions during the drying period of piles.

\begin{tabular}{|c|c|c|c|c|}
\hline Drying period (days) & Total precipitation (mm) & Mean air temperature $\left({ }^{\circ} \mathrm{C}\right)$ & Mean wind speed $\left(\mathrm{m} \mathrm{s}^{-1}\right)$ & Mean solar radiation $\left(\mathrm{W} \mathrm{m}^{-2}\right)$ \\
\hline Initial-30 & 105 & 17.9 & 0.62 & 171.5 \\
\hline $30-90$ & 44 & 18.2 & 0.90 & 272.7 \\
\hline $90-126$ & 151 & 19.4 & 0.93 & 320.5 \\
\hline
\end{tabular}

Table 3

Effect of particle size on moisture content and storage temperature of uncovered and non-ventilated wood chips piles.

\begin{tabular}{|c|c|c|c|c|c|c|c|c|c|c|c|c|c|}
\hline \multirow[t]{3}{*}{ Parameters } & \multirow{3}{*}{$\begin{array}{l}\text { Drying period } \\
\text { (days) }\end{array}$} & \multicolumn{12}{|c|}{ Wood chip length } \\
\hline & & \multicolumn{4}{|l|}{$5 \mathrm{~mm}$} & \multicolumn{4}{|l|}{$15 \mathrm{~mm}$} & \multicolumn{4}{|l|}{$30 \mathrm{~mm}$} \\
\hline & & Surface & Intermediate & Center & Mean \pm SD & Surface & Intermediate & Center & Mean \pm SD & Surface & Intermediate & Center & Mean \pm SD \\
\hline \multirow{4}{*}{$\begin{array}{l}\text { Moisture Content (wet } \\
\text { basis - \%) }\end{array}$} & Initial & 48.8 & 58.1 & 59.4 & $55.4 \pm 5.8 a$ & 45.5 & 58.4 & 58.8 & $54.2 \pm 7.6 a$ & 43.4 & 60.3 & 59.7 & $54.5 \pm 9.6$ \\
\hline & 30 & 55.2 & 61.5 & 56.5 & $57.7 \pm 3.3 \mathrm{a}$ & 44.5 & 66.1 & 63.5 & $\begin{array}{l}58.0 \pm 11.8 \\
\mathrm{a}\end{array}$ & 56.8 & 67.9 & 66.0 & $63.6 \pm 6.3 a$ \\
\hline & 90 & 27.0 & 54.7 & 60.3 & $\begin{array}{l}47.3 \pm 17.8 \\
a\end{array}$ & 44.1 & 60.7 & 57.0 & $53.9 \pm 8.7 a$ & 39.2 & 68.8 & 63.4 & $\begin{array}{l}57.1 \pm 15.8 \\
a\end{array}$ \\
\hline & 120 & 32.5 & 52.2 & 60.6 & $\begin{array}{l}48.4 \pm 14.4 \\
\mathrm{a}\end{array}$ & 38.1 & 52.5 & 51.9 & $47.5 \pm 8.2 \mathrm{a}$ & 31.7 & 55.6 & 58.7 & $53.5 \pm 6.6 a$ \\
\hline \multirow{4}{*}{$\begin{array}{l}\text { Storage Temperature } \\
\left({ }^{\circ} \mathrm{C}\right)\end{array}$} & Initial & 36.0 & 36.4 & 37.0 & $36.5 \pm 0.5 a$ & 34.1 & 36.9 & 34.9 & $35.3 \pm 1.4 \mathrm{a}$ & 31.0 & 35.0 & 36.8 & $34.3 \pm 3.0$ \\
\hline & 30 & 40.3 & 44.1 & 43.9 & $42.8 \pm 2.1 \mathrm{a}$ & 37.3 & 38.6 & 38.4 & $38.1 \pm 0.7 b$ & 29.8 & 31.5 & 31.3 & $30.9 \pm 0.9 c$ \\
\hline & 90 & 27.2 & 36.4 & 37.8 & $33.8 \pm 5.8 \mathrm{a}$ & 31.8 & 36.7 & 31.7 & $33.4 \pm 2.9 \mathrm{a}$ & 27.2 & 33.4 & 34.8 & $31.8 \pm 4.0$ \\
\hline & 120 & 34.3 & 36.1 & 38.0 & $36.1 \pm 1.9 \mathrm{a}$ & 37.2 & 36.6 & 35.3 & $36.4 \pm 1.0 \mathrm{a}$ & 34.3 & 36.1 & 38.0 & $36.1 \pm 1.9$ \\
\hline
\end{tabular}

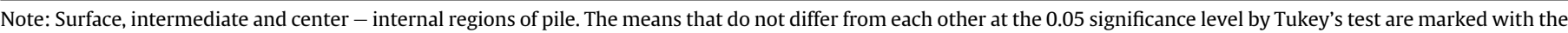
same letters at same rows.

transported immediately after harvesting instead storing at the field.

The pile temperature obtained was between $30.9^{\circ} \mathrm{C}$ and $42.8^{\circ} \mathrm{C}$, which was corroborated by the comparison with the previous studies with wood chips [9,19]. The temperatures were equal statistically, except at 30 days of drying period that it was observed lower results for wider wood chip length. This trend was clearly observed by Jirjis [20] who studied the influence of chip size and height of wood chip pile in the willow storage (Salix viminalix) in Sweden. In addition, low temperatures are important to control the self-heating in the storage systems.

\subsection{Effect of covering storage}

The coverage system obtained MC below 35\% and can be an alternative than uncovered storage (Fig. 2). In addition, a decrease of temperature was observed and it may contribute to decrease the biological degradation.

Due the fact of collecting samples from several internal positions in the pile, the standard deviation of MC at covered pile over drying period indicate that drying inside the pile was more homogeneous than uncovered pile (Table 4).

Drying period of 90 days can be sufficient to reach the minimum MC on the covered storage and it is particularly associated with winter season.

Although the covered piles showed more efficient to reduce the MC and the temperature, the economic aspects should be conducted on further researches.

\subsection{Daily moisture change}

Among storage systems, higher DMC was assigned to covered pile, about $0.197 \%$ day $^{-1}$ in the first 30 days (Table 5 ).

The DMC of uncovered pile was higher in the 30-90 days period, which was the dry period of winter season, obtaining a decrease below of $10.4 \% \mathrm{MC}$ at $5 \mathrm{~mm}$ WTC pile. This loss is higher than whole conifers chips measured in Northern Europe, 2-3\% per month [10].

Concerning the tropical condition, the gains and losses of MC were more pronounced than reported by Sikanen et al. [18] studying energy wood forest storages in Finland who obtained the maximum and minimum DMC, $0.162 \%$ day $^{-1}$ and $-0.133 \%$ day $^{-1}$, respectively. 

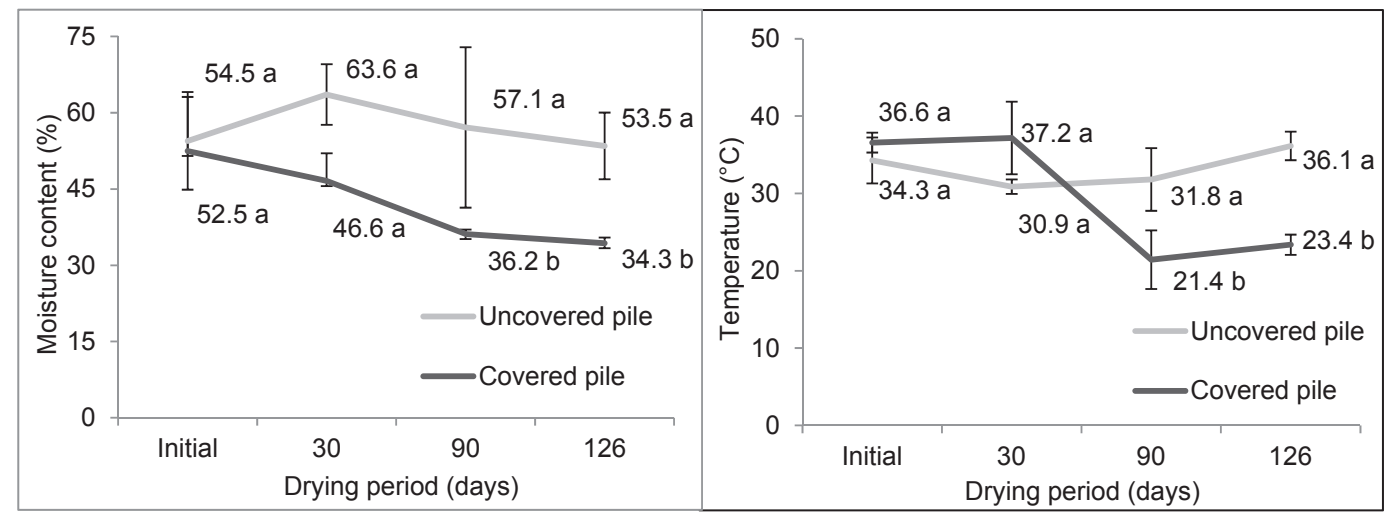

Note: The means that do not differ from each other at the 0.05 significance level by Tukey's test are marked with the same letters at the same drying period.

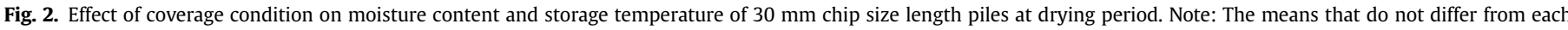
other at the 0.05 significance level by Tukey's test are marked with the same letters at the same drying period.

Table 4

Moisture content and storage temperature of covered pile.

\begin{tabular}{|c|c|c|c|c|c|}
\hline \multirow[t]{3}{*}{ Parameters } & \multirow[t]{3}{*}{ Drying period (days) } & \multicolumn{4}{|c|}{ Wood chip length } \\
\hline & & \multicolumn{4}{|c|}{30 mm (covered) } \\
\hline & & Surface & Intermediate & Center & Mean \pm SD \\
\hline \multirow[t]{4}{*}{ Moisture content (wet basis-\%) } & Initial & 40.7 & 61.4 & 55.4 & $52.5 \pm 10.6$ \\
\hline & 30 & 40.5 & 50.8 & 48.4 & $46.6 \pm 5.4$ \\
\hline & 90 & 36.2 & 37.0 & 35.3 & $36.2 \pm 0.9$ \\
\hline & 120 & 35.6 & 33.4 & 34.0 & $34.3 \pm 1.1$ \\
\hline \multirow[t]{4}{*}{ Storage temperature $\left({ }^{\circ} \mathrm{C}\right)$} & Initial & 35.1 & 37.5 & 37.1 & $36.6 \pm 1.3$ \\
\hline & 30 & 32.6 & 42.0 & 36.9 & $37.2 \pm 4.7$ \\
\hline & 90 & 18.2 & 20.5 & 25.6 & $21.4 \pm 3.8$ \\
\hline & 120 & 22.1 & 23.3 & 24.7 & $23.4 \pm 1.3$ \\
\hline
\end{tabular}

Table 5

Daily moisture change (\% units) of whole-tree chip piles in the drying periods.

\begin{tabular}{|c|c|c|c|c|}
\hline \multirow[t]{2}{*}{ Drying period (days) } & \multicolumn{4}{|l|}{ Wood chip length } \\
\hline & $5 \mathrm{~mm}$ (Uncovered) & 15 mm (Uncovered) & 30 mm (Uncovered) & $30 \mathrm{~mm}$ (Covered) \\
\hline Initial-30 & -0.076 & -0.127 & -0.304 & 0.197 \\
\hline $30-90$ & 0.173 & 0.069 & 0.108 & 0.174 \\
\hline $90-126$ & -0.030 & 0.177 & 0.101 & 0.051 \\
\hline
\end{tabular}

Although, the DMC obtained during the less rainy period were suitable to dry wood chips, the results were much lower those reported by Zanuncio et al. [14] monitoring debarked logs of Eucalyptus urophylla and Corymbia citriodora in Brazil, $0.611 \% \mathrm{day}^{-1}$ and $0.592 \%$ day $^{-1}$, respectively. The DMC of covered pile decreased over time of experiment, this trend can be associated to losses of drying rate of biomass when the equilibrium MC is being reached.

New studies have been prepared to evaluate the pile during the whole year under tropical conditions, also considering new approaches, e.g., different types of coverage and ventilated pile.

As strategy point of this paper, the DMC was associated with rainy period and can be adopted for further studies to divide the drying period in tropical conditions.

Although, this paper is one of few studies about whole-tree chips storage of eucalypt SRC established at tropical condition, it must be taken into consideration that moisture content and temperature inside the piles could have differently behave on larger piles and more replications are necessary to consolidate the effects and trends observed.

\section{Conclusions}

Whole-tree chip length was not effect on moisture content of non-ventilated and uncovered piles over drying period. For storage temperature, the greater chip length had effect only after 30 days of storage.

The coverage condition had beneficial effect on the drying period reaching MC lower than $35 \%$, conventionally recommended for energy purposes. Although, economic aspects should be taken into consideration.

Hence, this paper can be used as a reference paper for further studies on whole-tree chip storage at tropical conditions.

\section{Acknowledgements}

The authors would like to thanks the Coordination for the Improvement of Higher Education Personnel (CAPES), Sao Paulo State University - College of Agricultural Sciences (UNESP-FCA) and Laboratory of Agroforest Biomass Bioenergy (LABB). The authors 
also acknowledge the support of Case New Holland (CNH) and Marrari Industrial Automation.

\section{References}

[1] S.P.S. Guerra, E.A. Garcia, K.P. Lanças, M.A. Rezende, R. Spinelli, Heating value of eucalypt wood grown on SRC for energy production, Fuel 137 (2014) 360-363.

[2] R. Spinelli, S. Ward, P. Owende, A harvest and transport cost model for Eucalyptus spp. fast-growing short rotation plantations, Biomass Bioenergy 33 (2009) 1265-1270.

[3] L. Pari, et al., Influence of chipping device and storage method on the quality of SRC poplar biomass, Biomass Bioenergy 51 (2013) 169-176.

[4] E. Willebrand, S. Ledin, T. Verwijst, Willow coppice systems in short rotation forestry: effects of plant spacing, rotation length and clonal composition on biomass production, Biomass Bioenergy 4 (1993) 323-331.

[5] J.L. Stape, et al., The Brazil Eucalyptus Potential Productivity Project: influence of water, nutrients and stand uniformity on wood production, For. Ecol. Manag. 259 (2010) 1684-1694.

[6] IBA, Statistics of the Brazilian Tree Industry, Report 2015, Brazilian Tree Industry, Brasília, 2015.

[7] A. Sosa, M. Acuna, K. Mcdonnell, G. Devlin, Controlling moisture content and truck configurations to model and optimise biomass supply chain logistics in Ireland, Appl. Energy 137 (2015) 338-351.

[8] X. HE, et al., Dry matter losses in combination with gaseous emissions during the storage of forest residues, Fuel 95 (2012) 662-664.

[9] M. Barontini, et al., Storage dynamics and fuel quality of poplar chips, Biomass
Bioenergy 62 (2014) 17-25.

[10] P.D. Kofman, Quality Wood Chip Fuel. Harvesting and Transportation, 6, COFORD, Denmark, 2006.

[11] R. Jirjis, Storage and drying of wood fuel, Biomass Bioenergy 9 (1995) $181-190$.

[12] P. Hakkila, Developing Technology for Large-scale Production of Forest Chips, Technology Programme, Report 5, Tekes, Finland, 2003.

[13] M.A. Brand, G.I.B. Muñiz, W.F. Quirino, J.O. Brito, Storage as a tool to improve wood fuel quality, Biomass Bioenergy 35 (2011) 2581-2588.

[14] A.J.V. Zanuncio, et al., Predicting moisture content from basic density and diameter during air drying of Eucalyptus and Corymbia logs, Maderas. Cienc. Technol. 17 (2015) 335-344.

[15] J. Schweier, G. Becker, Harvesting of short rotation coppice - harvesting trials with a cut and storage system in Germany, Silva Fenn. 46 (2012) 287-299.

[16] S.P.S. Guerra, G. Oguri, R. Spinelli, Harvesting eucalyptus energy plantations in Brazil with a modified New Holland forage harvester, Biomass Bioenergy 86 (2016) 21-27.

[17] ASTM E871-82, Standard Test Methods for Moisture Analysis of Particulate Wood Fuels, American society for testing and materials, West Conshohocken, 2006.

[18] L. Sikanen, D. Röser, P. Anttila, R. Prinz, Forecasting algorithm for natural drying of energy wood in forest storages, For. Energy Obs. Study Rep. 27 (2012).

[19] M. Manzone, P. Balsari, R. Spinelli, Small-scale storage techniques for fuel chips from short rotation forestry, Fuel 109 (2013) 687-692.

[20] R. Jirjis, Effects of particle size and pile height on storage and fuel quality of comminuted Salix viminalis, Biomass Bioenergy 28 (2005) 193-201. 